\begin{tabular}{|c|c|c|c|c|c|}
\hline MUNIBE Antropologia-Arkeologia & $n^{\circ} 71$ & $207-223$ & DONOSTIA & 2020 & ISSN 1132-2217 • elSSN 2172-4555 \\
\hline
\end{tabular}

\title{
Origen y desarrollo del Castillo de Irulegi (Valle de Aranguren, Navarra). Periodización y arquitectura de una fortaleza medieval en el Prepirineo
}

\author{
Origins and development of the Irulegi Castle \\ (Aranguren Valley, Navarre). Periodization and architecture \\ of a medieval fortress in the pre-pyrenean mountains
}

PALABRAS CLAVE: Arqueología, periodización, castillo, arquitectura, Reino de Navarra. GAKO-HITZAK: Arkeologia, periodizazioa, gaztelua, arkitektura, Nafarroako Erresuma. KEY WORDS: Archaeology, periodization, castle, architecture, Kingdom of Navarre.

\section{Mattin AIESTARAN(1,2), Javier BUCES(2), Daniel RUIZ-GONZALEZ ${ }^{(1,2)}$, Graciela PONCE-ANTÓN(3), Aitor PESCADOR ${ }^{(2)}$, Alfredo MORAZA(2), Jesús SESMA ${ }^{(4)}$, Jesús GARCÍA(4), Jose Antonio MUJIKA-ALUSTIZA(1), JuantXo AGIRRE-MAULEON(2)}

\section{RESUMEN}

El castillo de Irulegi es uno de los ejemplos más destacados de castillos medievales del Reino de Navarra, localizado en la cima del monte que le dio nombre (Irulegi o Peña de Lakidain, Valle de Aranguren).

El castillo se erigió con fines defensivos y de control del territorio circundante entre el siglo XI y principios del XII. Desde entonces presenta una ocupación ininterrumpida hasta finales del siglo XV.

En cuanto a la evolución arquitectónica, destaca desde su origen la Torre del Homenaje pentagonal en proa. En la segunda mitad del siglo XIV fue objeto de una remodelación que transformó el castillo dotándolo de una planta rectangular con cinco torretas circulares ubicadas en sus esquinas que cambió la distribución interna de las estancias anexas a las murallas. Finalmente el castillo fue desmochado por Orden Real en 1494

\section{LABURPENA}

Irulegiko gaztelua Nafarroako Erresumako Erdi Aroko gazteluetan adibide hoberenetako bat da eta izen bereko mendiaren gailurrean kokatzen da (Irulegi edo Lakidaingo Harria, Aranguren Ibarra)

XI. mendearen eta XII.aren hasieran gauzatzen den gazteluaren eraikuntzak lurraldearen defentsa eta kontrola bilatzen zuen. Ordutik XV. mendera arte okupazio jarraitua erakusten du.

Hasierako gaztelutik branka edo erpindun dorre poligonala du ezaugarri nagusitzat. Garapen arkitektonikoari dagokionez, XIV. mendearen bigarren erdian, oinplano lau-angeluarrari jarraiki, ertzetan eta Dorre Nagusiaren ondoan bost dorre borobil eraiki ziren eta harresiei itsatsiriko eraikuntzen berrantolaketa bat burutu zen

Azkenik, 1494an eraitsi zuten gaztelua Errege-agindu baten ondorioz.

\section{ABSTRACT}

The Irulegi castle is one of the most outstanding examples of medieval castles in the Kingdom of Navarre, located on the top of the eponymous mountain (Irulegi or Lakidain rock, Aranguren Valley).

It is one of the few castles of Navarre that has been excavated almost in its entirety and has stratigraphic deposits collated with $\mathrm{C} 14$ dating.

The castle was erected for defensive purposes and for the control of the surrounding territory between the 11th and 12th centuries. Since its construction, it was continuously occupied till late 15th century.

Regarding its architectural evolution, its keep that consists of a pentagonal tower with a vertex that stands out. In the second half of the 14 th century five circular turrets were erected in its corners and next to the keep aligned in a rectangular plan. The internal distribution of the rooms attached to the walls was also changed. Finally, the castle was partially dismantled by royal order in 1494 .

The example of Irulegi and the comparison with other cases of its immediate surroundings, shows that diversity is the main characteristic of the castles of the Kingdom of Navarre.

\footnotetext{
(1) Universidad del País Vasco / Euskal Herriko Unibertsitatea. Grupo de Investigación en Prehistoria IT-1223-19. Centro de Investigación Micaela Portilla, calle Justo Vélez de Elorriaga 1, 01006 Vitoria-Gasteiz. Email: mdelasotilla001@ehu.eus

(2) Aranzadi Zientzia Elkartea / Sociedad de Ciencias Aranzadi

(3) Euskal Herriko Unibertsitatea / Universidad del País Vasco

(4) Gobierno de Navarra
} 


\section{INTRODUCCIÓN}

El conocimiento de la arquitectura defensiva medieval del Reino de Navarra cuenta con trabajos referenciales en el ámbito documental (Martinena, 1994, 2017) y trabajos arqueológicos de gran interés en villas fortificadas como Rada o el Cerco de Artajona (Cañada et al., 2005), e iglesias encastilladas como Ujue (Lazcano, 2011). También son de mencionar los conjuntos de redes de estructuras defensivas urbanas que cuentan con murallas, castillos y atalayas, como son las recientemente estudiadas de Lizarra-Estella (Ramos, 2015), de Tudela (Bienes, 2004), o de Iruñea-Pamplona (Faro, García-Barberena y Unzú, 2007-2008).

En referencia a los castillos, en el corazón del antiguo Reino de Navarra que a día de hoy supone en buena medida el territorio de la actual Comunidad Foral, encontramos algunos ejemplos que han sido recientemente estudiados mediante excavaciones arqueológicas (Fig. 1).

Sirven de ejemplo los de Amaiur en Baztan (Agirre-Mauleon, 2017a), Irurita o Sarabe en Urdiain (Satrustegui, 1973), Aitzita en Etxeberri, Ortzorrotz en
Ituren (Sagredo, 2018), Garaño en el Valle de Ollo (Sagredo, 2006), el castillo de Gorriti (Zabala, 2003), Deio en Villamayor de Monjardín (Ramos, 2012), Orraregi en Oskia (Castiella et al., 1999), el castillo de Monreal (Chafer, 2001), el de Ablitas (Bienes y Sola, 2015), el de Tiebas (Ramos, 2001), Miravalles en Huarte (Ramos, 2012), el castillo de Santacara (Del Olmo, 2014) y Peñaflor en Valtierra (García y Sesma, 2015).

Ejemplos estudiados recientemente mediante metodología arqueológica, de construcciones de características y problemáticas similares los encontramos también en tierras cercanas. Así por ejemplo, en la actual provincia de Gipuzkoa se pueden mencionar como ejemplos de lo comentado los castillos roqueros de Aitzorrotz en Eskoriatza (Puyal, 2019), Ausa Gaztelu en Zaldibia (Padilla, 2000), Beloaga en Oiartzun (Agirre-Mauleon, 2017b), el del túnel de San Adrián o paso de Lizarrate en Zegama (Tapia et al., 2009), Jentilbaratza en Ataun (Arrese, 2011) y Mendikute en Albiztur (Alvaro y Trave, 2019) ${ }^{1}$. Por su parte, en la actual comunidad de Bizkaia encontramos los casos que se han estudiado más recientemente de Aitziki en Abadiño

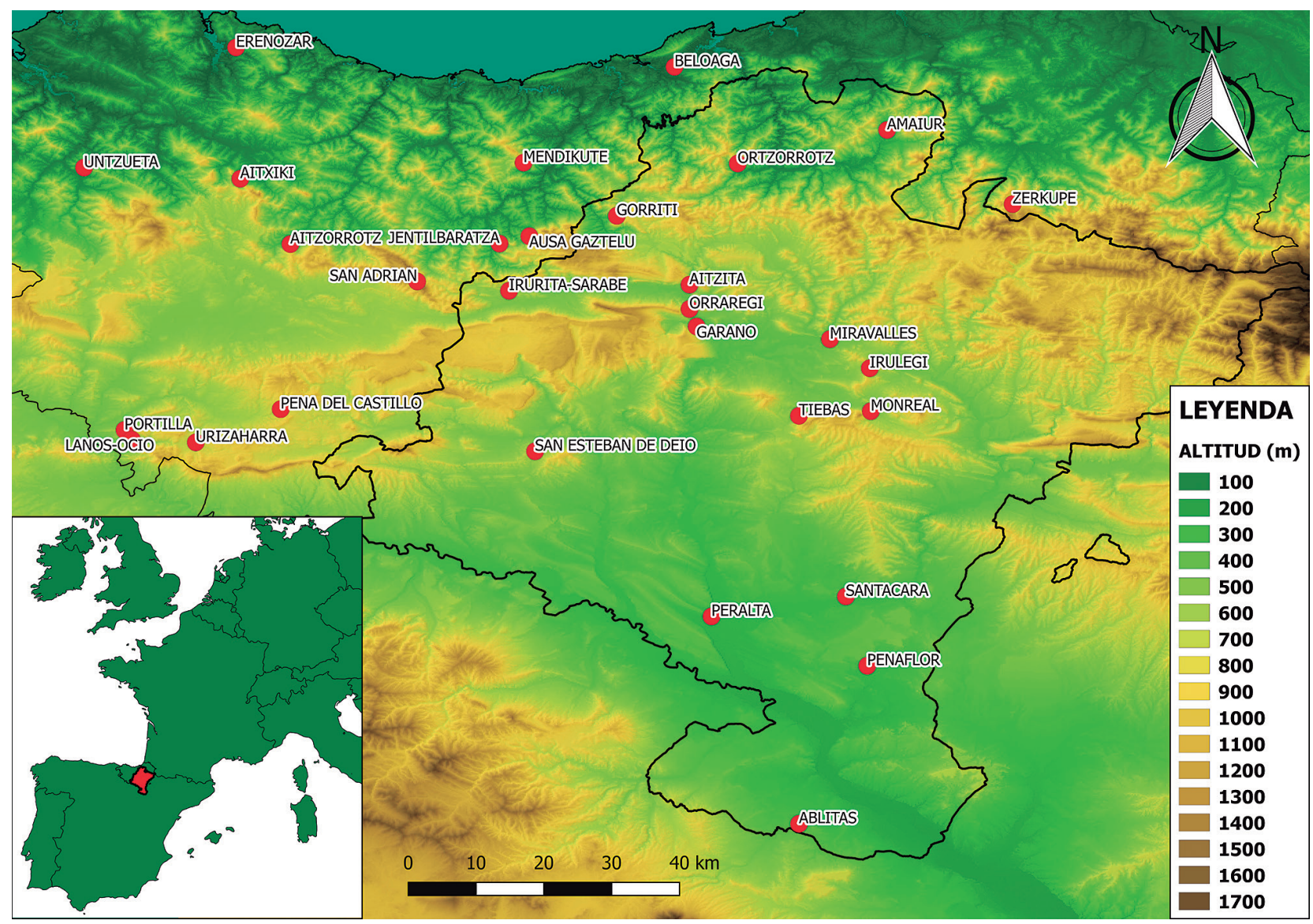

Fig.1. Castillos mencionados. Fuente de datos: GEAMAP y SITNA. / Castles mentioned. Data source: GEAMAP and SITNA.

1 Un amplio resumen de la evolución y características de los castillos de Gipuzkoa se encuentra en Sarasola (2010) y en Sarasola y Moraza (2011). 
(Garcia-Camino, 2004), el Castillo de Orozko (Solaun e Hidalgo, 2008) y Ereñozar en Ereño (Neira, 2010). En la actual Álava hay que mencionar el recientemente estudiado castillo roquero de Portilla en Zambrana (Solaun y Azcárate, 2016), aunque también hay que tener en cuenta los estudios en Marquínez (Azkarate y Solaun, 2007), el castillo de Urizaharra (Plata y Solaun, 2009) y en el de Ocio (Solaun, 2002). Por último, en las antiguas tierras de Ultrapuertos -la actual Saint-Michel (Behe Nafarroa)- encontramos el castillo roquero de Zerkupe, situado a más de mil metros (Marticorena et al., 2013).

A pesar de estos trabajos, las fases cronológicas y evoluciones arquitectónicas son poco concretas, ya sea por no haberse excavado en su integridad ningún recinto, por no contar con depósitos estratigráficos coherentes que cuenten con suficientes dataciones absolutas $^{2}$, o por la presencia de alteraciones posdeposicionales como la reutilización de materiales y la superposición de estructuras modernas.
Uno de los ejemplos más destacados es el del castillo de Irulegi, localizado en la cima del monte que le da nombre (Irulegi o Peña de Lakidain, Valle de Aranguren). Geográficamente, el castillo se encuentra situado en una zona denominada como valle Prepirenaico, entre los Pirineos y río Ebro, a las puertas orientales de la comarca geográfica conocida como Iruñerria o Cuenca de Pamplona (Nuín y Borja, 1991). El yacimiento se localiza en el extremo este del valle de Aranguren (coordenadas ETRS89: 621711 - 4737612), más o menos en la parte central de la actual Comunidad Foral de Navarra, a escasos 3 kilómetros de la capital Iruñea/Pamplona.

El castillo de Irulegi es uno de los pocos casos de la geografía navarra que ha sido excavado casi en su integridad y cuenta con depósitos estratigráficos cotejados con dataciones absolutas. Gracias a la abundante documentación histórica desde el siglo XIII, este castillo constituye un buen ejemplo para comparar y complementar los distintos registros (Fig. 2).

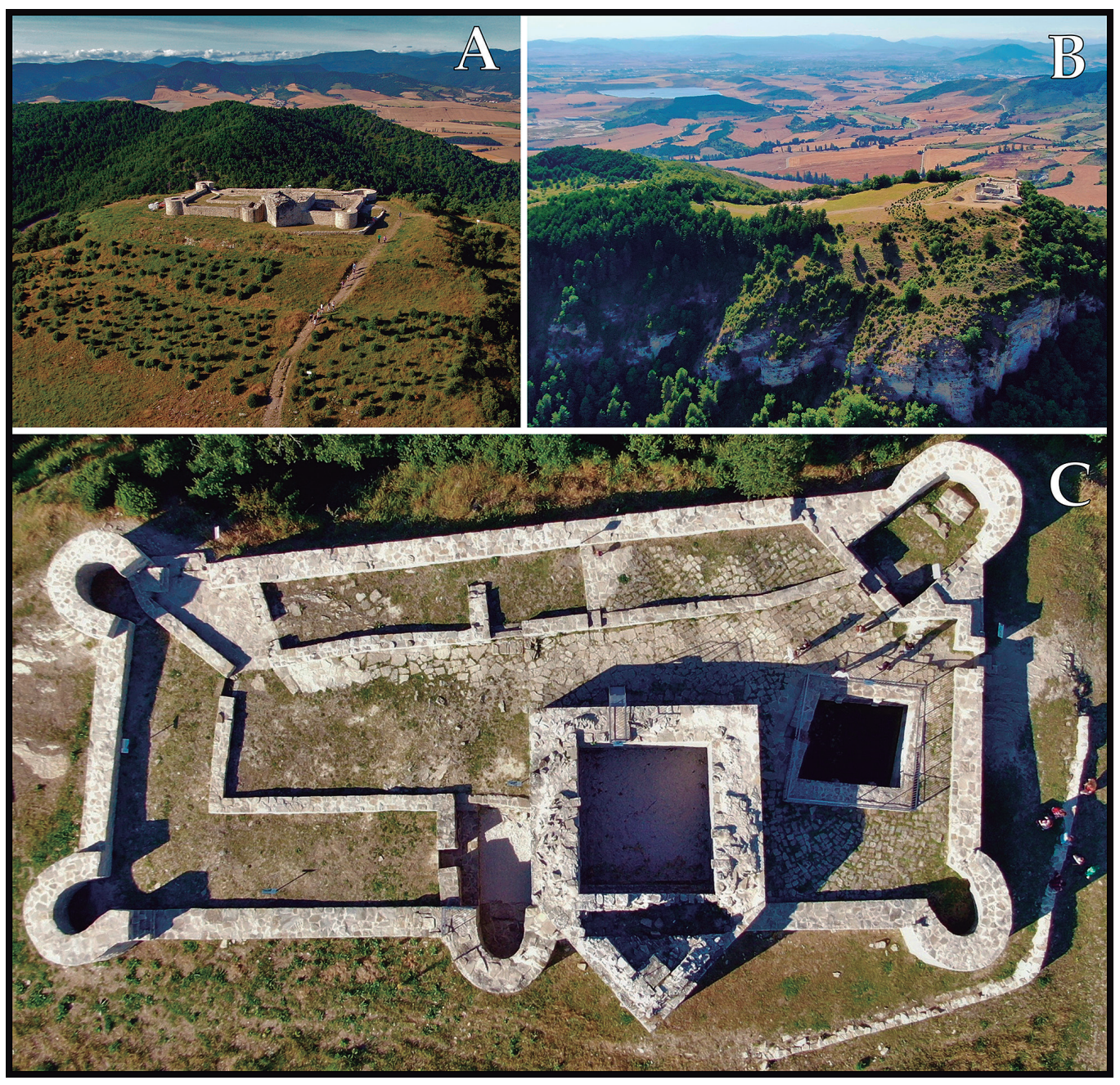

Fig.2. Fotografías del castillo de Irulegi. A: imagen orientada hacia el norte; $\mathrm{B}$ : imagen orientada hacia el oeste; C: imagen cenital orientada hacia el norte. Sociedad de Ciencias Aranzadi. / Photographs of the castle of Irulegi. A: image oriented north; B: image oriented to the west: C: zenithal image oriented to the north. Aranzadi Science Society.

2 En Navarra solamente cuentan con dataciones radiocarbónicas Irulegi y Deio. En Deio hay dos dataciones, $1527 \pm 26$ BP (436-530 AD, dos sigmas) y $1114 \pm 28$ BP (776-881 AD, dos sigmas), OxCal v4.4.2 Bronk Ramsey (2020); r: 5 Atmospheric data from Reimer et al. (2020). 
El yacimiento cuenta con un nivel de conservación alto, debido a la ausencia de alteraciones posdeposicionales y la superposición de estructuras modernas sobre las medievales. Dado que fue desmochado y sellado en 1494, el yacimiento muestra la disposición original de los elementos desde finales de sigo XV.

\section{OBJETIVOS}

Mediante el análisis de este caso concreto, se ha buscado arrojar algo de luz hacia la concreción de las fases cronológicas y evoluciones arquitectónicas de los castillos roqueros navarros y finalmente, conocer más a fondo este tipo de yacimientos característicos, y por lo tanto, la sociedad medieval.

Para ello, en el presente trabajo se plantearon los siguientes dos objetivos concretos: conocer el origen y fijar una periodización para el castillo de Irulegi, y analizar la anatomía y características del castillo en sus distintas fases desde los distintos niveles arqueológicos y restos arquitectónicos, comparándolo con distintos yacimientos de su entorno.

Se ha dejado para un trabajo posterior el estudio pormenorizado de los materiales arqueológicos.

\section{METODOLOGÍA}

Las excavaciones y el registro arqueológico y arquitectónico del castillo de Irulegi de las sucesivas campañas del 2007 al 2013 han seguido el método general de excavación y registro compendiado por Harris (1991), que ha sido descrito, junto con más detalles metodológicos, por Carandini (1997). A su vez, todo este procedimiento metodológico ha sido aplicado en las dos últimas campañas (2016 y 2017) a través del método simplificado desde el Museum of London Archaeology (MOLA, 1994).

Por otra parte, se ha realizado una revisión bibliográfica sobre los castillos parecidos y cercanos a Irulegi para contextualizar los resultados obtenidos en dicha fortaleza.

\section{DESCRIPCIÓN}

En estas líneas se describirán las características generales de los castillos mencionados en la introducción, para después exponer el caso concreto de Irulegi y profundizar en él.

\subsection{Panorama general de las fortificaciones medievales del reino de navarra y su entorno}

Se presenta a continuación el panorama general de las características más relevantes de los castillos medievales aludidos en la introducción y mostrados de forma individual en la tabla I del anexo, incluyendo los datos de Irulegi que se expondrán con más detalle en los siguientes apartados. La muestra no es cuantitativamente numerosa (30 castillos en total), pero se ha preferido ofrecer los datos en porcentajes para señalar mejor las tendencias generales.

Desde el punto de vista cronológico, tan solo el $16 \%$ de los casos mencionados tienen el origen arqueológicamente atestiguado anterior al siglo XI, el $43 \%$ de los casos entre los siglos XI y XII, y el $40 \%$ son de cronologías del siglo XIII o posteriores. Todos se mantienen hasta los siglos bajomedievales y el $40 \%$ se mantiene hasta el periodo moderno.

Respecto a las características generales, el 60\% tiene planta de morfología irregular, el 30\% tiene plantas regulares y tan solo un 10\% tiene planta rectangular.

En cuanto a los elementos arquitectónicos, todos tienen muralla, el 40\% torres menores, el 53\% aljibe, el $63 \%$ estancias anexas, y tan solo el $13 \%$ de los casos tiene patios de armas enlosados. Las Torres de Homenaje del $50 \%$ de los casos son rectangulares, el $16 \%$ son circulares, el 30\% no dispone de Torre del Homenaje y la torre de Irulegi es la única de morfología pentagonal en proa.

Tan solo el castillo de Ablitas, Santacara e Irulegi tienen todos los elementos propios de los castillos denominados románicos como murallas, Torre del Homenaje, torres menores, aljibe, estancias anexas, capilla y patio de armas. Aparte de todo ello, Irulegi es el único castillo en el que se ha hallado un horno.

\subsection{Resultados de las intervenciones en Irulegi 2007-2011}

En la primera campaña de 2007 se realizó una trinchera en la ladera bajo el castillo, en la cual se hallaron restos de un importante poblamiento de la Edad del Hierro. Estos datos están siendo reinterpretados en la actualidad (Aiestaran y Ruiz, 2020) y se ha preferido no incluirlos en este artículo que trata de la fortificación medieval.

El castillo ubicado en la cima del monte Irulegi presenta los siguientes elementos estructurales defensivos ya descritos en un trabajo anterior (Buces et al. 2013) (Fig 3):

- Torre del Homenaje de tipo pentagonal en proa. Aparte de esta obra, el conjunto de muros con aparejo pseudoisódomo parecen sincrónicos, ya que en los aparejos regulares y de gran calidad de la torre no se aprecian diferencias compositivas. No obstante, lo que sí se aprecian son numerosas grietas y cuantiosos arreglos. Los restos de los muros recuperados de la Torre del Homenaje tienen una anchura media de aproximadamente unos dos metros y una altura superior a tres metros desde su base, superando los cuatro metros de altura en su pared del lado sur. 


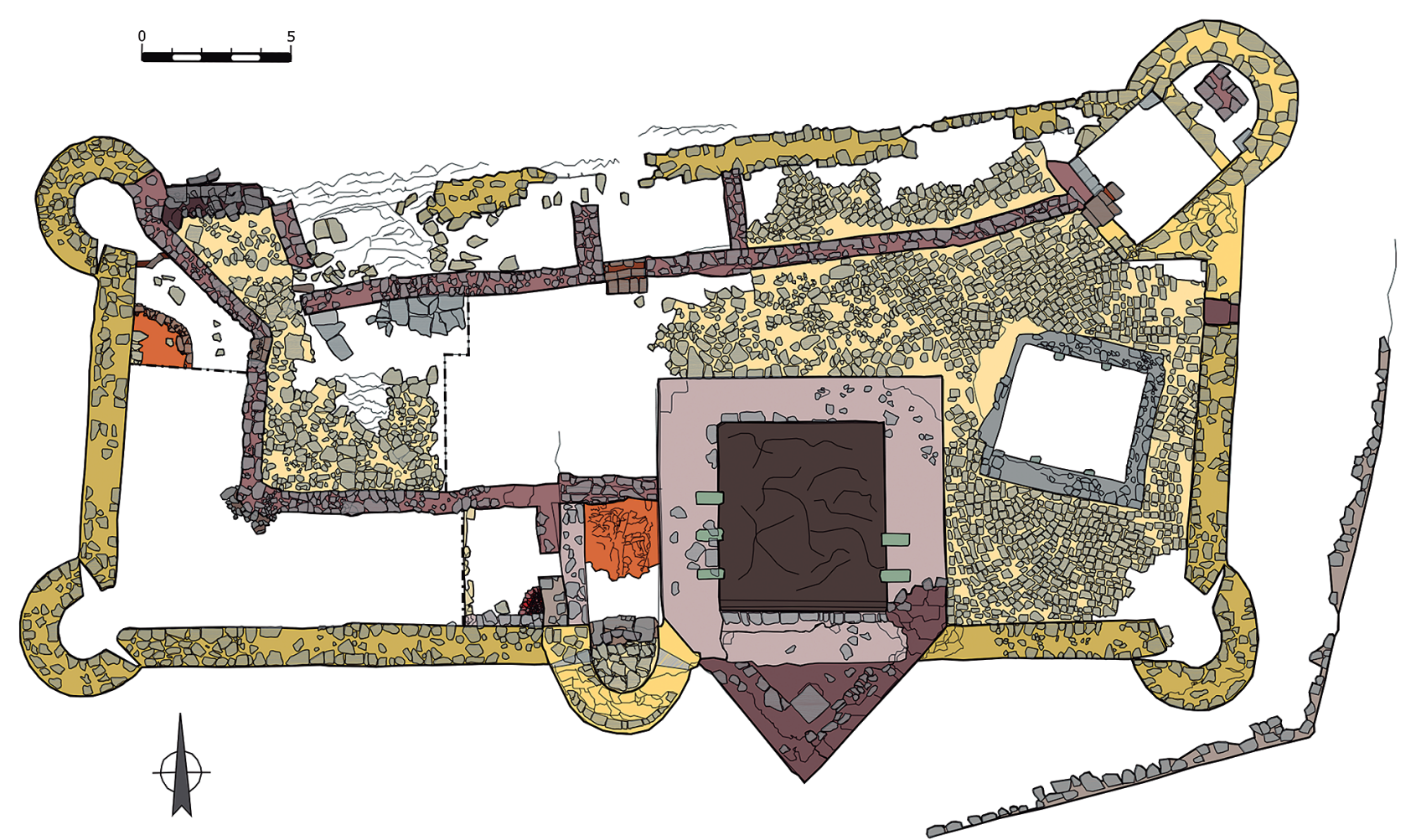

Fig.3. Planimetría del castillo de Irulegi. Sociedad de Ciencias Aranzadi. / Planimetry of the castle of Irulegi. Aranzadi Science Society.

- Muralla de cierre este, oeste y sur, con sus cinco torres circulares en los vértices y en el centro de la muralla sur. En total, comprende aproximadamente 136 $m$ de perímetro que cubren intramuros una superficie de $569 \mathrm{~m}^{2}$, incluidas la Torre del Homenaje y otras estructuras internas. El lienzo sur es el que mejor se ha preservado y muestra más acondicionamientos y reparaciones. Las cinco torres menores de morfología circular se situaban en los lienzos de las murallas, en las esquinas o a cierta distancia una de la otra. En el lienzo este se halló un portón de reducidas dimensiones.

- Falsabraga. Consta de dos hiladas de sillarejo irregular colocados a hueso sobre la roca natural en dos lienzos que miden unos 27 metros aproximadamente. Se ubica en paralelo a la muralla de cierre este y sur, formando un pasillo aproximadamente de tres metros de anchura.

- Estancias del norte. Se ubican paralelas a la muralla norte y aprovechan dicha defensa para adosarse a ellas. De este a oeste, las estancias se dividen en tres recintos (1200, 1190 y 2550). Todas estas estructuras aparecen superpuestas al enlosado (UE 1101), proponiendo para ellas una cronología de principios del siglo XV.

- Enlosado de la zona este. Se halló por primera vez en la zona noreste, al comenzar a excavar las estancias del norte. Contiene dos niveles de lajas de arenisca locales.

- Aljibe. De planta casi cuadrangular, está excavado directamente en la roca natural del terreno par- cialmente labrada. Sus dimensiones son de 3,85 por 4,25 metros, contando con una profundidad desde la superficie que oscila entre los 3,05 y los 3,50 metros, y una capacidad aproximada de unos 54.000 litros.

- Capilla norte. Aprovechando la torre semicircular de la esquina noreste se encuentra la estancia interpretada como capilla del castillo de Irulegi, la cual abarca una superficie aproximada de 20 metros cuadrados y tiene una morfología cuadrangular que termina en un semicírculo. Muestra su altar y ábside orientados hacia el este.

- Estancia del sur anteriormente interpretada como Capilla sur. Estructura pétrea de planta rectangular con un apéndice que termina en forma circular por la torre menor. Este murete de aparejo irregular, arranca desde la Torre del Homenaje en dirección oeste, en paralelo a la muralla sur, y presenta características similares en todo su recorrido. El proceso de excavación efectuado en este recinto de $14 \mathrm{~m}^{2}$ aporta la identificación de diferentes períodos constructivos y ocupacionales. En cuanto a la finalidad del edificio, la hipótesis anterior le atribuía una posible función religiosa.

\subsection{Resultados de las intervenciones en Irulegi 2016-2017}

Por otra parte, las intervenciones de 2016 y 2017 han deparado los siguientes novedosos resultados (Aiestaran y Buces, 2017; Buces y Aiestaran, 2016) (Tabla I y Fig. 4): 


\begin{tabular}{|c|c|c|c|c|c|c|}
\hline REF. & LAB. & TIPO DE MUESTRA & DATACIÓN BP & DATACIÓN Cal. (2 sigmas) & LUGAR DE MUESTREO & FUENTE \\
\hline IRULEGI 1028K4 & Ua-43255 & Carbón & $971 \pm 30$ & $1021-1159$ & Primera estancia sur & Buces et al. 2013 \\
\hline IRULEGI 1025K2-3 & Ua-43256 & Carbón & $685 \pm 30$ & $1050-1262$ & Primera estancia sur & Buces et al. 2013 \\
\hline IRULEGI 4023 & Ua-57852 & Hueso & $815 \pm 30$ & $1175-1275$ & Segunda estancia sur & Inédito \\
\hline IRULEGI 1011D5 & Ua-43253 & Carbón & $492 \pm 30$ & 1404-1452 & Torre del Homenaje & Buces et al. 2013 \\
\hline IRULEGI 1022K1 & Ua-43254 & Carbón & $415 \pm 30$ & $1429-1621$ & Primera estancia sur & Buces et al. 2013 \\
\hline CHARCOAL & AAR-28207 & Carbón & $691 \pm 22$ & $1270-1385$ & Torre del Homenaje & Ponce et al. 2020 \\
\hline Cl-T-9B.1 & ETH-89320 & Mortero & Fuera de rango & Fuera de rango & Torre del Homenaje & Ponce et al. 2020 \\
\hline Cl-T-9B.2 & ETH-89329 & Mortero & $31 \pm 23$ & 1891-1909 & Torre del Homenaje & Ponce et al. 2020 \\
\hline Cl-T-9B.3 & ETH-89330 & Mortero & $324 \pm 25$ & $1485-1644$ & Torre del Homenaje & Ponce et al. 2020 \\
\hline Cl-T-9T.1 & ETH-89547 & Mortero & $119 \pm 25$ & 1680-1939 & Torre del Homenaje & Ponce et al. 2020 \\
\hline Cl-T-9T.2 & ETH-89548 & Mortero & $256 \pm 22$ & 1527-1799 & Torre del Homenaje & Ponce et al. 2020 \\
\hline Cl-T-10B.1 & ETH-87870 & Mortero & $911 \pm 26$ & $1034-1186$ & Torre del Homenaje & Ponce et al. 2020 \\
\hline Cl-T-10B.2 & ETH-87861 & Mortero & $1136 \pm 24$ & $777-983$ & Torre del Homenaje & Ponce et al. 2020 \\
\hline Cl-T-10B.3 & ETH-87862 & Mortero & $1801 \pm 24$ & $132-322$ & Torre del Homenaje & Ponce et al. 2020 \\
\hline Cl-T-10T.1 & ETH-89549 & Mortero & $1095 \pm 25$ & 891-1012 & Torre del Homenaje & Ponce et al. 2020 \\
\hline Cl-T-10T.2 & ETH-89550 & Mortero & $1645 \pm 27$ & $335-533$ & Torre del Homenaje & Ponce et al. 2020 \\
\hline Cl-T-13B.1 & ETH-89321 & Mortero & $491 \pm 28$ & $1406-1449$ & Torre del Homenaje & Ponce et al. 2020 \\
\hline Cl-T-13B.2 & ETH-89322 & Mortero & $1082 \pm 25$ & $895-1017$ & Torre del Homenaje & Ponce et al. 2020 \\
\hline Cl-T-13B.3 & ETH-89331 & Mortero & $2155 \pm 27$ & 356-100 A.C. & Torre del Homenaje & Ponce et al. 2020 \\
\hline Cl-T-13T.1 & ETH-89551 & Mortero & $633 \pm 26$ & 1286-1397 & Torre del Homenaje & Ponce et al. 2020 \\
\hline Cl-T-13T.2 & ETH-89552 & Mortero & $1033 \pm 24$ & $973-1030$ & Torre del Homenaje & Ponce et al. 2020 \\
\hline
\end{tabular}

Tabla 1: Dataciones radiocarbónicas del Castillo de Irulegi. / Radiocarbon dating of the Irulegi Castle. OxCal v4.4.2 Bronk Ramsey (2020); r: 5 Atmospheric data from Reimer et al. (2020).
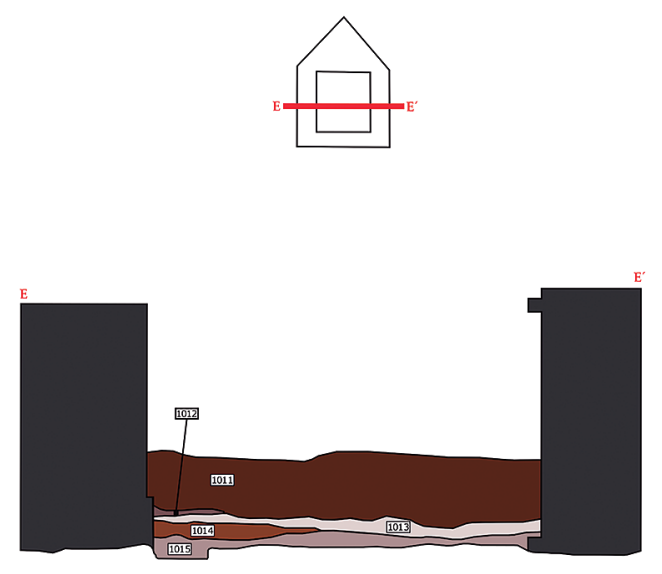
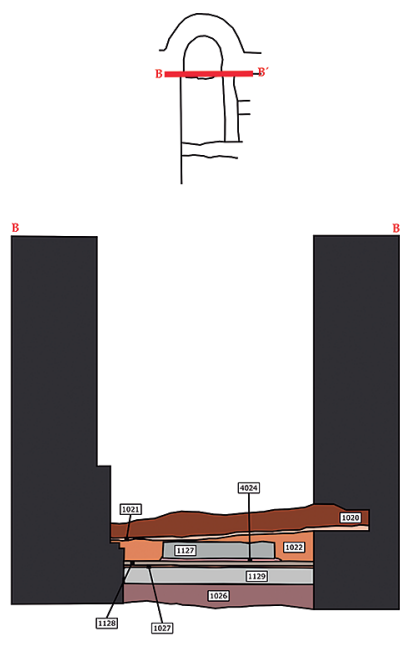

$\longrightarrow$.
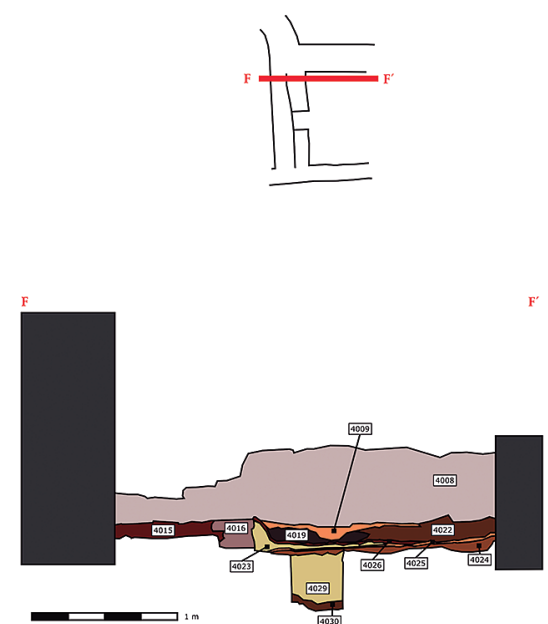

Fig.4. Perfiles estratigráficos de las estancias del sur. De izquierda a derecha: perfil de la Torre del Homenaje, perfil de la primera estancia del sur y perfil de la segunda estancia del sur. Sociedad de Ciencias Aranzadi. / Stratigraphic profiles of the southern rooms. From left to right: Profile of the keep, profile of the first southern room and profile of the second southern room. Aranzadi Science Society.

- Muralla del norte. En el lado norte se encuentra el acantilado y, por ello, es la zona más fácil de defender. En él se han hallado restos deficientemente conservados, pero que muestran que el muro mantenía las mismas características que en los demás sectores.

- Entrada del noroeste. En el lienzo de la muralla norte (UE 1140), hacia su lado oeste, se han hallado los restos de lo que fuera una puerta de considerables dimensiones. En este sentido, se ha localizado una estancia enlosada (UE 1101) y bastante bien conservada de aproximadamente 9,6 $\mathrm{m}^{2}$, cuya función probablemente fuera la de vestíbulo o estancia tras el acceso principal.

Sobre dicho enlosado, se halló el gozne, de $22 \mathrm{~cm}$ de diámetro, de la mencionada puerta, tallado en una 
sola pieza sobre un sillar de 36 × $39 \times 40 \mathrm{~cm}$. Se localizaba junto a los sillares colocados a modo de escalones (UE 4056) en la zona noroeste, los cuales denotan cierto desgaste por haberse pisado repetidamente durante periodos prolongados.

- Estancias del noroeste. Entre la muralla perimetral oeste y el vestíbulo que da a la entrada, se encuentra una estancia que comunica a la torre circular noroeste (UE 1180) mediante el escalón dispuesto para ello (UE 4052). Este ámbito fue parcialmente excavado, ya que solamente se retiraron los niveles superficiales (UE 1001) y niveles de derrumbe (UE 1002). Se desconoce la superficie que llegó a abarcar hacia el lado sur, ya que no se llegó a encontrar límite alguno. De todos modos, la extensión conocida de este espacio es de aproximadamente $11 \mathrm{~m}^{2}$. La estancia está adosada a la muralla del lado oeste y formada por los muretes internos (UE 4053 y UE 4054) que se dirigen hacia el vestíbulo y hacia el patio de armas. En su unión se encuentra la entrada a la estancia (UE 4055). Apareció bien definida, ya que está conformada mediante un escalón que desciende directamente del patio de armas. En esta estancia se pudo evidenciar una estructura pétrea semicircular (UE 4050) adosada a la muralla oeste, la cual en su interior tenía un nivel de arcilla con signos de termoalteración (UE 4051), sin que fueran demasiado destacados. Este hecho contrasta con la ausencia de carbones que existe en el interior y alrededor de esta estructura. Abarca una superficie aproximada de 3,7 $\mathrm{m}^{2}$ y un radio de 2 metros, pero posiblemente la mitad de esta estructura continúa debajo del sedimento más allá del límite de la excavación.

- Patio de armas. El enlosado del patio de armas abarca una superficie aproximada de $42 \mathrm{~m}^{2}$ y ha aparecido bastante más deteriorado que el resto.

- Segunda estancia del sur. Es de una superficie actualmente desconocida, ya que solamente se excavaron $8 \mathrm{~m}^{2}$ sin encontrar su final hacia el lado oeste. En esta estancia se hallaron prácticamente las mismas unidades estratigráficas del primer recinto, encontrando niveles rubefactados muy similares a las del primer ámbito (Fig. 5).

\section{ESTANCIA SUR I}

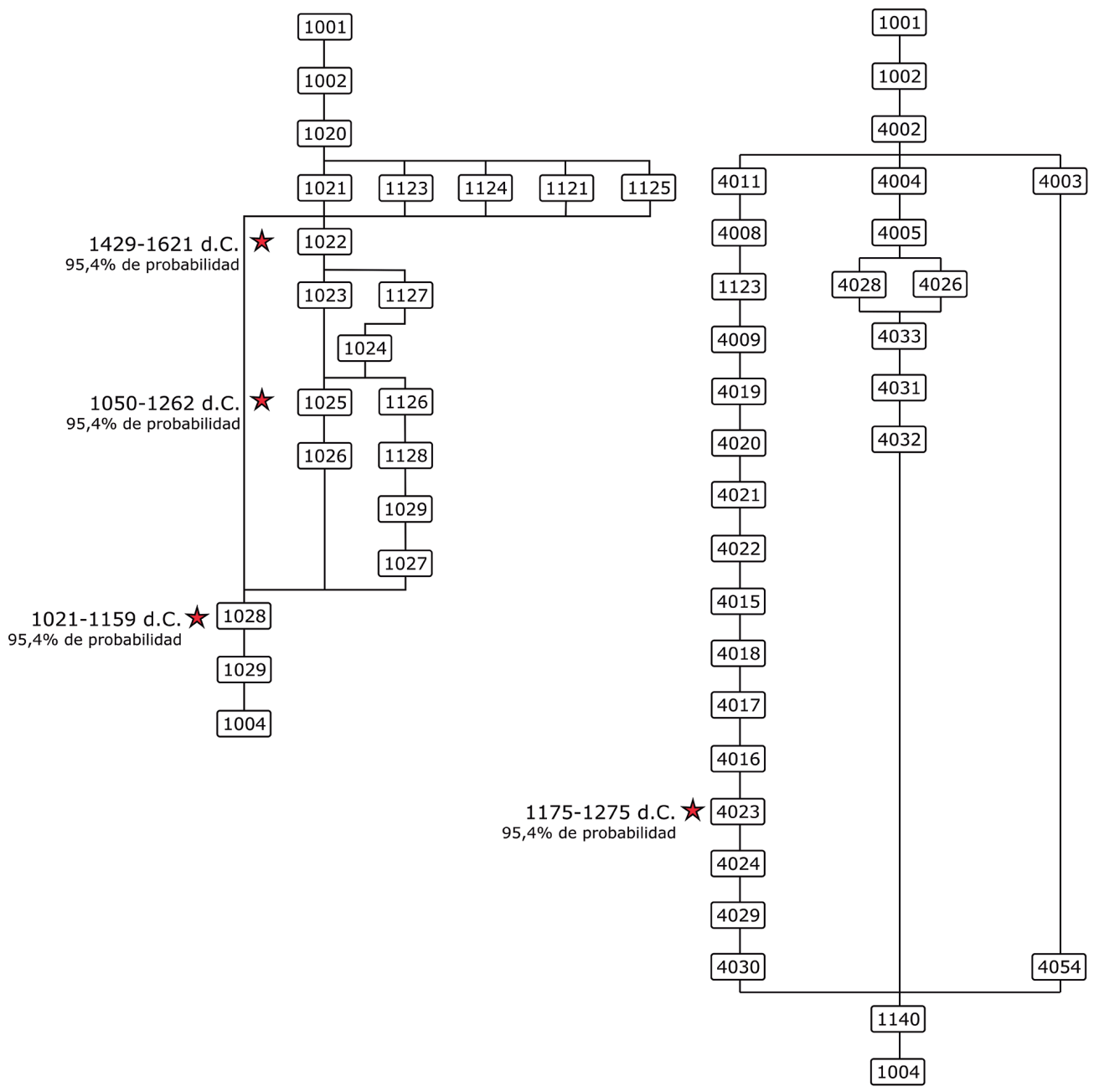

ESTANCIA SUR II

Fig.5. Matrix estratigráficos de las estancias del sur. Stratigraphic matrix of the southern rooms. 
Dichas unidades correspondían a un momento anterior al siglo XV, en el que las dos estancias no se encontraban separadas, y adosado al muro principal se hallaba un horno (UE 4016) de morfología circular que fue excavado parcialmente. Este horno parece ser una de las estructuras internas más antiguas del castillo, ya que, bajo sus niveles de abundantes inclusiones de carbón y signos de rubefacción homogénea de más de $5 \mathrm{~cm}$ de potencia (UE 4024), hallamos un resto óseo de ovicáprido datado por radiocarbono en el siglo XII. La solera del horno se formó con lajas poliédricas de calcarenita local (5 x $10 \times 4 \mathrm{~cm}$ de media de tamaño), que aparecen con signos de rubefacción y colación morada por el intenso calor (UE 4017). No hallamos la embocadura, pues erigieron sobre parte de esta estructura de combustión un murete interno (UE 1123) en época posterior (Fig. 6).
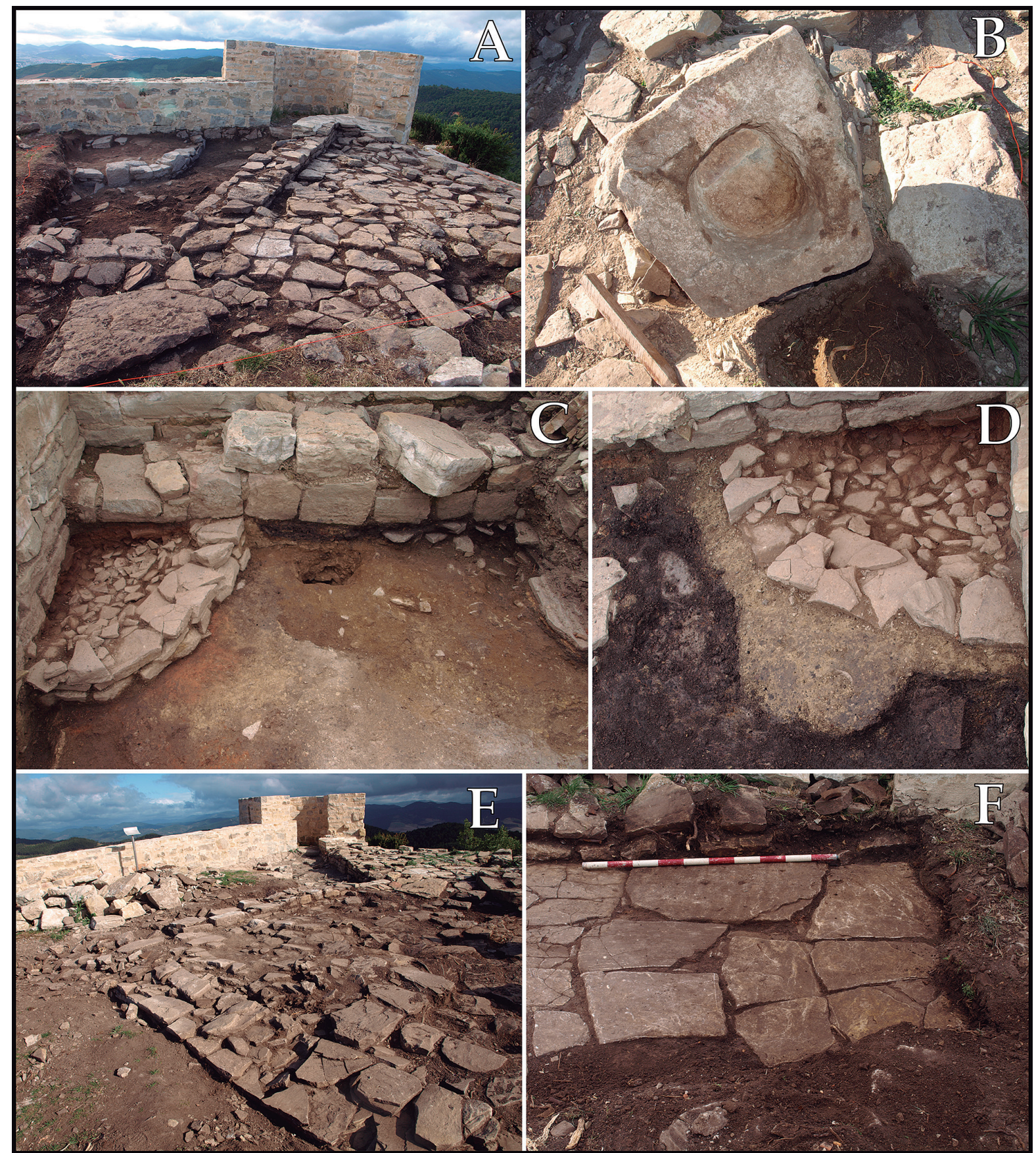

Fig.6. Fotografías de los resultados de la intervención de 2017. A: zona noroeste; B: gozne de la entrada principal noroeste; C: segunda estancia del sur; D: horno; E: patio de armas; F: enlosado del patio. Sociedad de Ciencias Aranzadi. / Photographs of the results of the intervention of 2017. A: northwest area; B: northwest main entrance hinge; C: second room from the south; D: oven; E: parade square; F: flagstone pavement of the parade square. Aranzadi Science Society. 
Junto a este horno pudimos encontrar restos de una distribución interna distinta y anterior a la del siglo XV, pudiéndose reconocer una unidad negativa a modo de agujero de poste (UE 4004) y restos de una posible compartimentación de yeso y lajas (UE 4020), ligeramente rehundidos respecto a la cota del suelo de uso.

\section{DISCUSIÓN}

Tras haber intervenido en un área extensa del castillo de Irulegi y haber analizado su estratigrafía y arquitectura, a continuación se tratará de fijar una periodización para el castillo de Irulegi, y se interpretarán la anatomía y características del castillo en sus distintas fases en base al análisis de los sistemas constructivos y los restos de cultura material mencionados anteriormente. Conjuntamente, se discutirán los datos descritos sobre los castillos de Navarra y su entorno.

\subsection{Período 1 (siglos XI-XIII)}

En el caso de Irulegi no se han recuperado datos directos de los periodos tardoantiguo y altomedieval en el área del castillo, como sí ha ocurrido en alguna fortificación del entorno (Tejado, 2010). De este modo, el período que aporta los restos arqueológicos y las dataciones radiocarbónicas más antiguas corresponde a los siglos plenomedievales que abarcan las centurias XI y XIII. En este aspecto, se han tomado en cuenta las dataciones de materiales orgánicos hallados en contexto estratigráfico ${ }^{3}$ y se ha preferido no tener en cuenta en la interpretación las dataciones de los morteros de cal, ya que las muestras pueden estar viciadas por restos de caliza antigua o restos orgánicos, o rejuvenecidas por una recristalización posterior del carbonato.

Por consiguiente, Irulegi encaja bien dentro de lo que se ha denominado como modelo de castillo plenomedieval de "tercera generación" (Quirós y Tejado, 2012), ya que se erige a partir del siglo XI y tiene un reflejo importante en las fuentes escritas.

Este periodo nos ha proporcionado como mayor evidencia arquitectónica las características generales del castillo. Pero hablando de vestigios considerables concretos, no va más allá de partes de elementos estructurales y algún material arqueológico adscribible a estos siglos que han sido cubiertos por los sedimentos posteriores ${ }^{4}$. Sin embargo, resulta de vital importancia el hecho de que hayan sido localizados, puesto que ofrecen una valiosa información acerca de las primeras cronologías del castillo de Irulegi.
Estos restos se han obtenido en las zonas interiores del castillo en las que se ha conservado una secuencia estratigráfica de cierta entidad -estancias del sur- debido a que no se han visto afectadas gravemente por las acciones posdeposicionales, como las posibles remociones posteriores que hubieran podido barrer los restos anteriores.

La Torre del Homenaje también pertenece a esta época, también habiendo quedado reflejado en la composición de los morteros de cal utilizados para tal fin (Ponce et al., 2020). Su arquitectura peculiar en su lado sur, lo define como "torre pentagonal en proa" (Mora-Figueroa, 2006). Este tipo de atalayas, tanto de flanqueo como exentas, muestran como característica más destacada la planta que les da nombre y que resulta de prolongar la superficie de una torre cuadrangular (observable en el caso de Irulegi) con un esperonte o vértice que cubre por completo una de sus caras. Este modelo en Europa es de influencia bizantina, ya que en Francia este aspecto poliorcético se desarrolla desde el siglo XI, tomado de las cruzadas. Sirve como ejemplo la torre de Moncada del siglo XIII en Orthez (Sagredo, 2006). El concepto de torre pentagonal en proa puede observarse concretamente en la comarca del Sobrarbe (Huesca), donde se encuentran los ejemplares más primitivos de esta tipología en los castillos de Arcusa, Azaba, Sarsa de Surta y Luzás entre otros. La datación de los mismos no está aún clara, pero el criterio artístico y arquitectónico y las referencias documentales señalan que su origen se remonta a los siglos XI-XII. Estas torres no formaban parte de una primera línea de defensa (como Loarre, Ujué etc.) de Sancho Garcés III el Mayor (1004-1035) frente a la Taifa de Zaragoza. Aparecen como torres aisladas pertenecientes a una segunda línea de control y aviso (Castán, 2019).

Pese a los ejemplos presentados, en la geografía navarra el de Irulegi es el único caso de torre pentagonal. A pesar de no contar con evidencias arqueológicas claras en esta cuestión y basarse solamente en criterios artísticos y arquitectónicos, no parece descabellado el hecho de que el donjon de Irulegi encajara desde el origen en esta tipología y formara parte de una parecida línea de control y aviso del siglo XI o XII5. Jimeno Jurío (2006: 34) señala bien el contexto del reino al decir que "Desde el siglo XI, la Corona obtiene importantes recursos del oro de las parias, invertidos en la construcción de las fortalezas, pagos de soldados y gastos suntuarios de la corte."

La construcción de las dos torres pentagonales de Alarcos (en Ciudad Real) en 1193 marca el inicio del uso de este tipo de torres con su máxima difusión a partir del siglo XIV, pudiéndose encontrar en otras re-

\footnotetext{
${ }^{3}$ Las muestras orgánicas datadas proceden de restos de vida corta (fragmento óseo) y de vida relativamente corta como carbones de ramas poco gruesas. Estos últimos pudieran retrasar algo esas dataciones por el efecto de madera antigua.

${ }^{4}$ Es importante mencionar el hallazgo de una moneda de Luis IV de Francia (936-954) en las estancias del norte.

5 Precisamente de estos siglos datan las tipologías de los materiales arqueológicos medievales más antiguos hallados en Irulegi.
} 
giones peninsulares como Toledo (Castillo de Montalván) o Ávila (Castillo de Madrigal de las Altas Torres) (Gil, 2013), áreas geográficas que se alejan de la zona de Irulegi (Fig. 8). Todo ello evidencia que el de Irulegi no es un caso aislado, si bien no se han documentado otros ejemplos en su entorno geográfico inmediato.

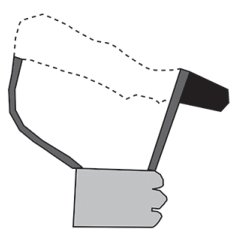

LUESIA (ZARAGOZA)

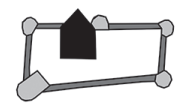

IRULEGI (NAVARRA)

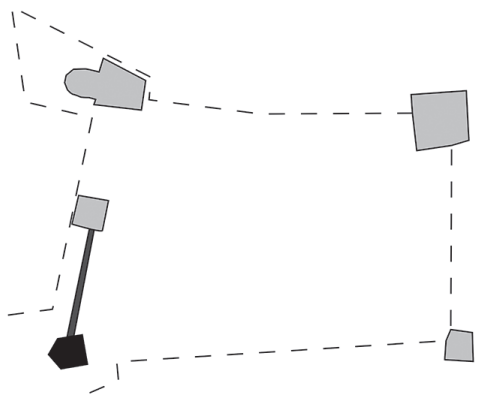

AINSA (HUESCA)
$0 \mathrm{~m} \quad 20 \mathrm{~m} \quad 40 \mathrm{~m}$

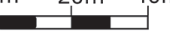

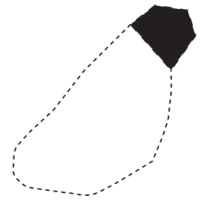

TRONCEDO (HUESCA)

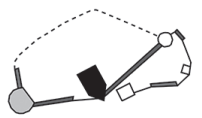

ALMORCHÓN (BADAJOZ)

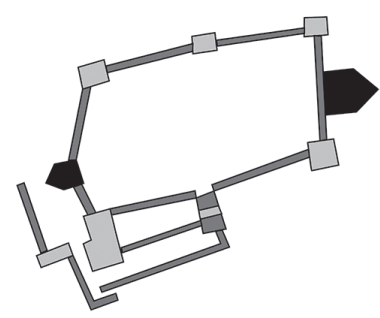

ALARCOS (CIUDAD REAL)
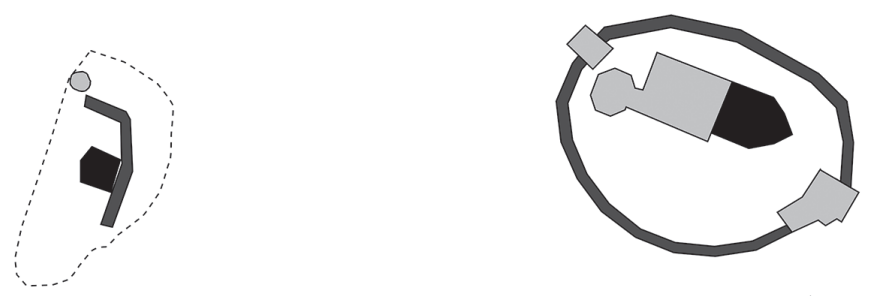

CHATEAU MONCADE (BEARN)

\section{CASTILLO DE LUZAS (HUESCA)}
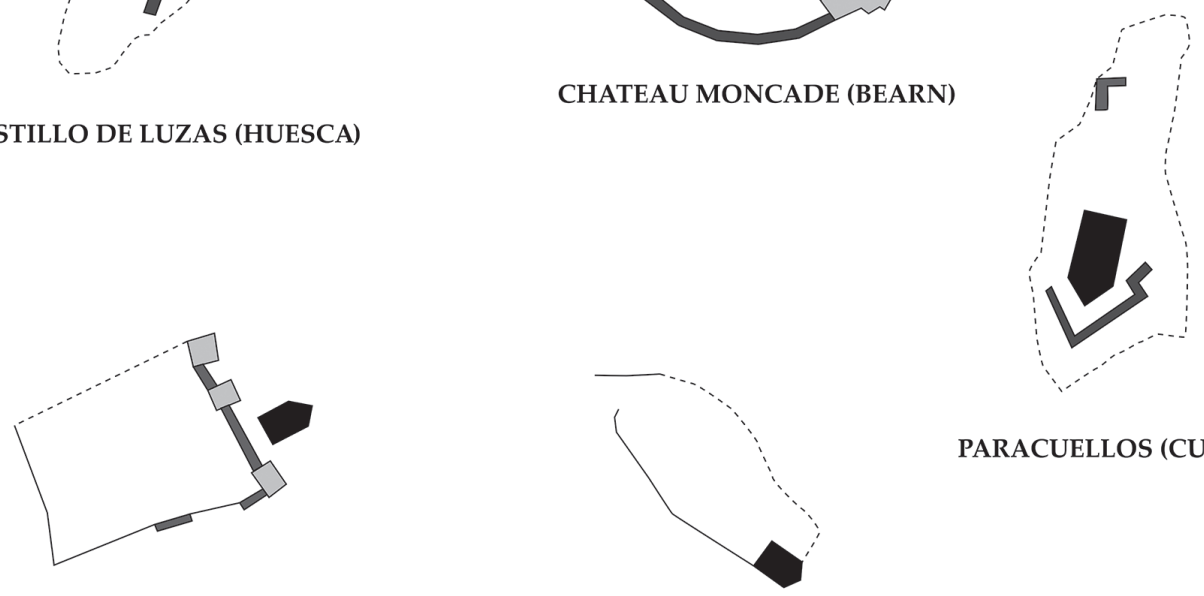

CARACUEL DE CALATRAVA (CIUDAD REAL)

Fig.7. Plantas esquemáticas de las torres pentagonales mencionadas en el texto. Fuente cartográfica: GEAMAP. / Schematic plans of the pentagonal towers mentioned in the text. Cartographic source: GEAMAP. 
La torre pentagonal en proa impedía las maniobras de ataque del enemigo, ya que ese ángulo muerto desaparecía y cualquiera que lograra acercarse a la torre estaría en todo momento expuesto a ser atacado desde las demás murallas o las torres. Además, el acusado ángulo del vértice frontal desviaría con gran facilidad los proyectiles lanzados por los ingenios enemigos (catapultas, onagros, etc.) (Mora-Figueroa, 2006).

Este tipo de torres no siempre encierran un recinto interior con la misma planta, sino que el muro que adquiere la forma adelantada incrementa su grosor, sin variar el perímetro cuadrangular de la sala interior (Gil, 2013).

Tras los tipos de mota y bailey o las atalayas de los siglos altomedievales (Moraza et al. 2003) y fortificaciones se fueron modificando hasta aparecer los famosos donjon-s (o keeps en los territorios anglosajones), grandes torreones de piedra y una muralla circundante, a menudo irregular para adaptarla al terreno (Ramos, 2000). Los típicos ejemplos de donjon-s circulares en el reino de Navarra se encuentran en el conocido como Cerco de Artajona (Cañada et al., 2005) y el desolado de Rada (Tabar, 1994; 1996). Sin embargo, la Torre del Homenaje de Irulegi también fue considerada de tipo donjon según la documentación de la época (Martinena, 2017), aunque no fuera cilíndrica.

En cuanto a la organización arquitectónica, se ha registrado una distribución anterior a la que se observa actualmente en la segunda estancia del sur, junto al horno adosado a la muralla. Atendiendo a su contexto arqueológico descartamos la función productiva artesanal, ya que no se encontró ni en el horno ni en sus inmediaciones residuos, escorias o ningún desecho de cualquier actividad productiva, aunque sí se hallaron diversos niveles de carbón superpuestos en su alrededor. Es por ello que cabría esperar una función alimentaria. Su tamaño reducido, con un radio inferior a un metro, coincide con los tamaños de los hornos domésticos tradicionales en zonas cercanas (Iriarte, 2016). La bóveda está construida en piedra y tierra, sin ser excavada en el sustrato. Los distintos niveles de carbón hallados indican que se extraían las brasas del interior del horno una vez alcanzaba la temperatura necesaria para cocer los alimentos, aprovechando así la cualidad irradiante de la arcilla. Aparte de cocer pan, pudo haber sido utilizado para secar o tostar alimentos cuando la temperatura disminuía, como se han venido utilizando los hornos domésticos tradicionales en el territorio (Jimeno Jurío, 2016).

La intensa rubefacción causada no es fruto del gran tamaño del horno y parece que ha influido más la duración de la exposición al fuego, la alta temperatura alcanzada y sobre todo la recurrencia de hornadas (Bruley-Chabot y Warme, 2009). Por lo tanto, podemos especular que este horno fue utilizado durante varios siglos, desde finales del siglo XII o comienzos del XIII, hasta las remodelaciones del siglo XV.
En cuanto a paralelos, se han hallado parecidos casos de delimitaciones por pequeñas lajas de yeso hincadas en el horno altomedieval de Congosto (Vigil-Escalera, 2012). Como en el ejemplo, el agujero de poste cercano a la cámara de morfología circular podría testimoniar una cubierta. Estos elementos señalan el deseo de protección del horno frente a la intemperie.

El horno difiere con la estructura circular delimitada con piedras de la estancia noroeste, ya que este segundo se puede definir como hogar, por la ausencia de rubefacción. De este modo, el hogar de la estancia del noroeste tendría una función de control de fuego, para cocinar, calentar o alumbrar (Cañavate, 2008).

La continuación hacia el oeste de esta estancia aneja al primer recinto, con casi idénticas unidades en su interior, nos hace pensar que habría estancias como ésta anexas a toda la muralla sur, sobre todo teniendo en cuenta que no hemos hallado el final de este ámbito hacia el oeste.

\subsection{Período 2 (siglos XIV y XV)}

La atalaya o el simple donjon de las primeras centurias se suplantará o se complementará con la tipología románica o fórmula conocida como de «Felipe Augusto». Esta tipología, extendida hacia el año 1200 desde Francia (aunque llegó a implantarse en los reinos penisulares hacia el siglo XIV), tiene como base fundamental una planta rectangular delimitada por torres de flanqueo, unidas a su vez por muros-cortina de igual altura, con paseo de ronda o adarve y estancias adosadas a los muros perimetrales, conformando el centro un patio central (Cabodevilla, 2018).

Es muy probable que ciertas características de esta tipología de castillo fueran implantadas en el Reino de Navarra en torno al primer tercio del siglo XIV, ya que uno de los ejemplos más tempranos de Aragón para la tipología «Felipe Augusto» lo constituye el castillo de Sádaba en el siglo XIII (Martínez, 1987).

Para construir este tipo de fortalezas era necesario que el terreno se adaptara al edificio y no al revés. Los que han sido intervenidos arqueológicamente en Navarra y en las inmediaciones (Fig. 1) siguen mayoritariamente el patrón de adaptación al terreno sobre el que se asientan y, a pesar de su heterogeneidad material y funcional, son comunes los castillos roqueros de planta irregular y dimensiones modestas que contienen elementos estructurales simples como un recinto, un aljibe y una torre, tal y como se ha expuesto en la descripción. Estos castillos han sido interpretados en términos funcionales como marcadores territoriales (Quirós y Tejado, 2012)

En Irulegi se labra la rampa de acceso y el conjunto adquiere cierto grado de complejidad con todos los elementos y estancias mencionadas, de modo que, pese a que no siguen al pie de la letra el modelo intitulado con el nombre del soberano francés, sí que se 
distingue una adaptación local. Se aprecia la transición del modelo de castillo arcaico como una torre principal pentagonal con un recinto amurallado del siglo XI, pasando a ser una especie de fortificación defendida por torres y muros en su periferia en el siglo XIV.

En ningún caso anterior mencionado, ni en Irulegi, parece que se produjera el fenómeno de incastellamento (Toubert, 1990), ya que no se encuentra próximo a ninguna población en época medieval. De todos modos, este tipo de castillos ejercían su influencia mediante el dominio regio y señorial en el paisaje circundante. Su función, además de la de vigilancia, era la de convertirse en hitos del poder regio, de su dominio, al ser vistos por los habitantes del territorio como una representación directa de la auctoritas de su señor.

La etapa bajomedieval, que abarca esencialmente los siglos XIV y XV, es la época en la que el castillo de Irulegi adquiere la distribución arquitectónica y arqueológica que se percibe en la actualidad. Esta distribución general ya venía configurada desde su erección, pero a lo largo del tiempo se produjeron reformas que dotaron de otras divisiones internas y diferentes funciones a los espacios ya delimitados en el periodo anterior (Fig. 8).

Un ejemplo de ello es el portón del lienzo este, que en comparación con la entrada principal del noroeste, es de un tamaño muy reducido y estratigráficamente posterior. La ubicación del tipo de acceso principal del castillo de Irulegi, junto a una torre y en un lateral aprovechando la orografía, está documentada también en otros recintos amurallados medievales de planta regular, como por ejemplo en Urizaharra (Plata y Solaun, 2009) o en Sádaba (Martínez, 1978).

Los siglos XIV y XV han proporcionado el mayor número de materiales arqueológicos y elementos arquitectónicos. La vida diaria, las contiendas y los conflictos vividos durante estos siglos se reflejaron tanto en la estructura del castillo mismo como en los materiales hallados en él. Es en este período cuando se pueden intuir las actividades de control y aviso que ejerció esta fortaleza, por el hecho de que la documentación constata diversas actividades bélicas (como las de 1378 o las de mediados del siglo XV), que van aumentando en los siglos bajomedievales (Martinena, 2017; Monteano, 1999).

Por otra parte, actualmente se conoce mejor el espacio del patio de armas adscribible a este periodo. Tras la medición y su estudio podemos confirmar que este patio tan característico de los castillos medievales, el cual se disponía sin cubierta a cielo abierto tenía una superficie de $42 \mathrm{~m}^{2}$. En comparación, por ejemplo, con el patio de armas del castillo navarro bajomedieval de Marcilla (Sesma y Tabar, 2001), puede decirse que el pavimento del empedrado de Irulegi no está realizado con cantos rodados de pequeño tamaño, sino que se trata de las lajas de arenisca locales. A través de este espacio, también conocido como «plaza de armas», se accedía a las demás dependencias y estancias del castillo y se solía utilizar para la instrucción militar de la guarnición. Precisamente, en castillos en los que se aprecian similitudes a la tipología «Felipe Augusto», este pavimento o plaza de armas solía estar habitualmente rodeado por diversas dependencias como podían ser las cuadras, viviendas, herrería, almacenes, etc., como sucede en Irulegi.

En cuanto a los espacios religiosos, el análisis pormenorizado de los depósitos arqueológicos de las dos estancias del sur por un lado, y la capilla norte por el otro, han arrojado cierta luz hacia la concreción de algunas hipótesis previamente planteadas. No vemos que a la primera estancia del sur, anteriormente llamada "capilla sur" (Buces et al. 2013), se le pueda atribuir función religiosa alguna. Reinterpretamos este espacio como toda una serie de estructuras permanentes ligadas a actividades de habitación y subsistencia.

Sin embargo, la capilla norte, parece a todas luces un espacio singular en este aspecto. Pese a estar inserto en una superestructura destinada a la función defensiva, era un espacio de culto religioso, cuestión fundamental para la cosmovisión de la época medieval. Así

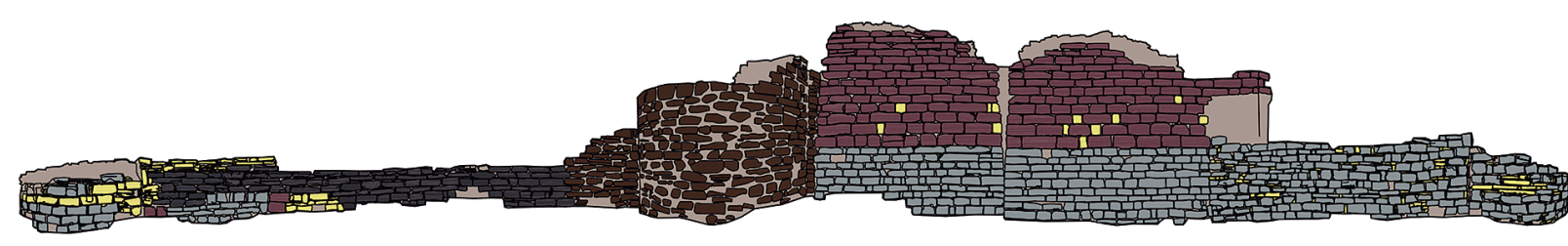

$0 \mathrm{~m}$ $5 \mathrm{~m}$
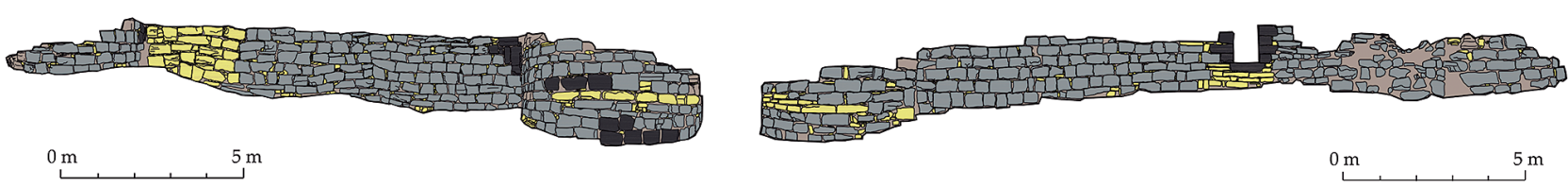

0 $5 \mathrm{~m}$

Fig.8. Alzados de las murallas de Irulegi. Sociedad de Ciencias Aranzadi. / Elevation of the walls of Irulegi. Aranzadi Science Society. 
lo atestiguan los adornos metálicos hallados en la base de su altar ${ }^{6}$. El hecho de que la cabecera esté orientada en una línea este-oeste y mirando hacia oriente, es debido a que dentro de la simbología de tradición cristiana se buscaba que el espacio de culto mirase hacia el lugar donde nació el Mesías, Jesucristo. Además, su orientación hacia la salida del sol (este) con el consiguiente simbolismo de vida-muerte-resurrección que supone para el cristianismo.

La vida del castillo de Irulegi terminó en 1494 por una orden dada el 12 de septiembre a Johan de Méharin por parte de los soberanos Juan III de Albret y Catalina de Foix. A la luz de los documentos históricos (Martinena, 2017), Juan de Garro y el Capitán Remonet fueron los encargados de formar una comisión para demoler el castillo el 24 de noviembre de 1494, reuniendo para tal fin a las gentes de alrededor de los pueblos. Aunque fuera ese el momento del desmantelamiento definitivo, ya en 1492 sus edificios habían sido derribados en buena medida debido a la política iniciada por los soberanos navarros para acabar con el conflicto civil que asolaba Navarra desde hacía casi cinco décadas. Para entonces ya se habían demolido los castillos de Rada, Rocafort o la torre de Luzaide-Valcarlos; siendo coetáneo a Irulegi el derribo de los castillos de Cáseda, Gallipienzo y Pintano (Pescador, inédito).

La destrucción de una fortaleza no era ni barata ni fácil, ya que su principal objetivo era ser fuerte y resistir los embates militares del enemigo. Por lo tanto, cuando se ordenaba el derribo de un castillo, no se derruía entero y hasta los cimientos, ya que resultaba muy costoso. Así pues, se procedía a desmocharlo, acción ésta que consistía en realizar en él las demoliciones necesarias para dejarlo inoperativo y sin capacidad defensiva. El proceso incluía dos acciones esenciales: descrestarlo o desmocharlo y desmantelarlo. En primer lugar, se derribaban sus almenas y el parapeto, reduciendo en caso necesario la altura de los muros. Luego se destruían las zonas y elementos fortificados más importantes, incluida la puerta, hasta dejarlo ineficaz para su defensa. En el caso de Irulegi, debió de llevarse a cabo el derribo de la Torre del Homenaje, el derribo parcial de las murallas y torres y el derribo total de la entrada principal. Con los restos constructivos desmantelados se procedió a tapar o colmatar el aljibe. La entidad de la estructura y sus elementos característicos -ménsulas que sobresalen de la estructura para poder soportar el peso en voladizo de una cubierta- nos hace suponer que, como los demás aljibes de otros castillos medievales como el de Monreal (Chafer, 2001) o Amaiur (Agirre-Mauleon, 2017a), el de Irulegi contaría con una cubierta abovedada que protegería el agua almacenada en el interior como señalan los fragmentos desmenuzados y mal conservados de vigas de madera halladas cerca del surco en las que pudieron apoyarse. Todo ello se ubicaba bajo un enorme único nivel de derrumbe que colmataba en su totalidad el aljibe de 54.000 litros de capacidad. La sedimentación no fue gradual ni casual, sino intencionada y masiva, lo cual ha privado a este castillo de ofrecer un registro de materiales inusuales.

Así pues, atendiendo a los casos expuestos en la descripción y a los aspectos mencionados del primer periodo del castillo de Irulegi, es necesario volver a la cuestión de la concreción de las fases cronológicas y evoluciones arquitectónicas de los castillos roqueros navarros.

Se puede apreciar, en relación a las fortificaciones plenomedievales del Reino de Navarra, que no hay tipologías arquitectónicas concretas, como sí los hay en las edificaciones religiosas que manteniendo sus particularidades, siguen algunas características comunes. El panorama en el ámbito de los castillos es mucho más diverso y cada caso parece atender a sus propias circunstancias coyunturales: ubicación geográfica general, función principal, ubicación concreta, contexto cronológico, etc. y tan solo en algunos casos se puede intuir una voluntad de seguir un diseño concreto, como puede ser la edificación de una torre de morfología de pentagonal en proa, que no parece ser para nada un fenómeno generalizado en el Reino.

\subsection{Período 3 (siglos XVI-XVII)}

Esta etapa se circunscribe a las centurias que transcurrieron tras el desmantelamiento del castillo en los últimos años del siglo XV. En toda la ladera, más allá de la cumbre, predominaron las actividades agropecuarias y no hay restos, salvo algún fragmento cerámico fuera de contexto, que nos haga pensar en una ocupación posterior. Según indican las fuentes documentales, pudo ser que el uso de la capilla siguiera vigente durante los años siguientes al abandono del castillo (Martinena, 2017), a pesar de que no hayan llegado restos materiales de entidad para sostener firmemente la perduración duradera de este espacio religioso.

El castillo de Irulegi fue en periodos anteriores ante todo una edificación defensiva. La vida diaria en él hacía necesario toda una serie de estructuras permanentes ligadas a actividades de habitación y subsistencia, además de los rituales religiosos. Estas actividades eran realmente necesarias para poder habitar en un entramado de muros defensivos situado en la cumbre de un monte, muy lejos de las comodidades que las nuevas arquitecturas palaciales ubicadas en las Ilanuras del valle, como la Torre de Aranguren o el Cabo de Armería de Góngora, podían ofrecer (Lizeaga, 2018).

\footnotetext{
${ }^{6}$ Tal y como se ha mencionado, el análisis pormenorizado de los materiales arqueológicos excede los límites de este texto y se dejan para otro trabajo
} 
Concluir señalando que tanto el abandono del castillo, como su posible posterior uso como ermita son fenómenos que se dan de forma global en el Reino (Pérez, 1983).

\subsection{Período 4 (siglos XVII-XXI)}

Las actividades agropecuarias han sido las únicas realizadas en los alrededores de donde antaño estuvo situado el castillo. Estos usos agrícolas pervivieron hasta el inicio del siglo XX, manteniéndose algunos como el pastoreo ocasional incluso en el siglo XXI.

\section{CONCLUSIONES}

Las últimas intervenciones en el castillo de Irulegi han aportado valiosa información acerca del origen y la periodización, así como de su anatomía y características generales.
La ubicación estratégica de Irulegi se vuelve a ocupar intensamente después de un hiatus de aproximadamente un milenio desde el final de la Edad del Hierro, ya que no se han recuperado datos directos del período tardoantiguo y altomedieval concernientes al castillo.

El castillo se erige, precisamente, persiguiendo los mismos fines defensivos o de aviso y de control del territorio circundante a finales del siglo XI o principios del XII. Pudo ser el poder regio el que ordenó construir la fortaleza, aunque no podamos más que sugerirlo por la falta de testimonios escritos. Sin embargo, el hecho de que se trate de un castillo real refuerza esta hipótesis.

El origen del castillo comienza como una Torre del Homenaje pentagonal en proa, pasando a ser una especie de fortificación defendida por muros y torres en su periferia hacia la mitad del siglo XIV. La planta del castillo adquiere la distribución arquitectónica y arqueológica que se percibe en la actualidad. En su anatomía

\begin{tabular}{|c|c|c|c|c|c|c|c|}
\hline NUM. & CASTILLO & CRON. & MORF. REGULAR & ALT. (m) & C14 & MURALLA & TORRE MAYOR \\
\hline 1 & ABLITAS-ABLITAS & $\mathrm{X}-\mathrm{XVI}$ & SI & 421 & NO & SI & CIRCULAR \\
\hline 2 & AITXIKI-ABADIÑO & $X I-X I I I$ & NO & 785 & $\mathrm{SI}$ & $\mathrm{SI}$ & NO \\
\hline 3 & AITZITA-ETXEBERRI & $X I I I-X V I$ & NO & 750 & NO & $\mathrm{SI}$ & RECTANGULAR \\
\hline 4 & AITZORROTZ-ESKORIATZA & $X I I-X V$ & NO & 736 & NO & $\mathrm{SI}$ & NO \\
\hline 5 & AMAIUR-BAZTAN & $X I I-X V I$ & SI & 365 & $\mathrm{NO}$ & $\mathrm{SI}$ & RECTANGULAR \\
\hline 6 & AUSA GAZTELU-ZALDIBI & XIII-XIV & $\mathrm{NO}$ & 899 & $\mathrm{NO}$ & $\mathrm{SI}$ & CIRCULAR \\
\hline 7 & BELOAGA-OIARTZUN & XII-XIV & SI & 266 & $\mathrm{NO}$ & $\mathrm{SI}$ & RECTANGULAR \\
\hline 8 & DEIO-VILLAMAYOR & $I X-X V$ & SI & 890 & SI & $\mathrm{SI}$ & RECTANGULAR \\
\hline 9 & ERENOZAR-GERNIKA & $\mathrm{XI}-\mathrm{XVI}$ & $\mathrm{NO}$ & 447 & SI & $\mathrm{SI}$ & RECTANGULAR \\
\hline 10 & GARANO-OLLO & $\mathrm{XI}-\mathrm{XVI}$ & SI & 593 & NO & $\mathrm{SI}$ & CIRCULAR \\
\hline 11 & GORRITI-GORRITI & XIII-XV & NO & 853 & $\mathrm{NO}$ & $\mathrm{SI}$ & RECTANGULAR \\
\hline 12 & IRULEGI-ARANGUREN & $X I I-X V$ & SI & 889 & SI & $\mathrm{SI}$ & PENTAGONAL EN PROA \\
\hline 13 & IRURITA-URDIAIN & XIII-XV & $\mathrm{NO}$ & 670 & $\mathrm{NO}$ & SI & $\mathrm{NO}$ \\
\hline 14 & JENTILBARATZA-ATAUN & XI-XIV & $\mathrm{NO}$ & 465 & $\mathrm{NO}$ & SI & RECTANGULAR \\
\hline 15 & LANOS-OCIO & $X I I-X V$ & $\mathrm{NO}$ & 644 & SI & SI & RECTANGULAR \\
\hline 16 & MENDIKUTE-ALBIZTUR & XII-XIV & $\mathrm{NO}$ & 814 & NO & SI & $\mathrm{NO}$ \\
\hline 17 & MIRAVALLES-UHARTE & $X I V-X V$ & SI & 594 & NO & $\mathrm{SI}$ & NO \\
\hline 18 & MONREAL-MONREAL & XIV-XVI & SI & 607 & NO & SI & CIRCULAR \\
\hline 19 & ORRAREGI-OSKIA & $\mathrm{XIII-XVI}$ & NO & 998 & NO & SI & CIRCULAR \\
\hline 20 & ORTZORROTZ-ITUREN & $\mathrm{XIII-XVI}$ & NO & 890 & $\mathrm{NO}$ & SI & NO \\
\hline 21 & PEÑA DEL CASTILLO-MARKINEZ & X-XIII/XIV & NO & 725 & SI & SI & NO \\
\hline 22 & PEÑAFLOR-VALTIERRA & $\mathrm{XIII-XV/XVI}$ & NO & 395 & $\mathrm{NO}$ & SI & RECTANGULAR \\
\hline 23 & PERALTA-PERALTA & $\mathrm{XII-XV}$ & SI & 377 & NO & SI & RECTANGULAR \\
\hline 24 & PORTILLA-ZANBRANA & $\mathrm{XI}-\mathrm{XVI}$ & NO & 780 & SI & SI & RECTANGULAR \\
\hline 25 & SAN ADRIAN-ZEGAMA & X-XIV & NO & 1000 & NO & SI & RECTANGULAR \\
\hline 26 & SANTACARA-SANTACARA & $\mathrm{XIII-XVI}$ & SI & 318 & $\mathrm{NO}$ & SI & RECTANGULAR \\
\hline 27 & TIEBAS-TIEBAS & XIII-XX & SI & 562 & NO & SI & $\mathrm{NO}$ \\
\hline 28 & UNTZUETA-OROZKO & XI/XII-XIV & $\mathrm{NO}$ & 766 & SI & $\mathrm{SI}$ & RECTANGULAR \\
\hline 29 & URIZAHARRA-URIZAHARRA & X-XIV & SI & 815 & NO & SI & RECTANGULAR \\
\hline 30 & ZERKUPE-SAINT MICHEL & $X V-X V I$ & NO & 1100 & NO & $\mathrm{SI}$ & $\mathrm{NO}$ \\
\hline
\end{tabular}

Tabla I del anexo: Características más relevantes de los castillos medievales de Navarra y su entorno, recientemente estudiados mediante excavaciones arqueológicas. / Most relevant characteristics of recently studied medieval castles of Navarre and surroundings 
sigue una tipología similar a la denominada románica, denotando una complejidad funcional y una planta regular ausente en los castillos roqueros circundantes.

El ejemplo de Irulegi y su comparación con otros casos del entorno geográfico cercano, muestra que la diversidad es la característica principal de los castillos del Reino de Navarra, cuyas morfologías y desarrollos arquitectónicos parecen responder a coyunturas y causas concretas, salvando los evidentes rasgos generales que cualquier fortificación medieval pueda tener

Pese a conocer mejor este castillo, es evidente la necesidad de seguir investigando y excavando para profundizar en el conocimiento de estas construcciones características. Estas investigaciones abarcarían los procesos constructivos, su estructuración, tradición arquitectónica, abandonos y reutilizaciones.

Asimismo, es necesario realizar un estudio pormenorizado de los materiales arqueológicos con el fin de conocer mejor el pasado del yacimiento de Irulegi.

\section{AGRADECIMIENTOS}

Agradecemos al Ayuntamiento del Valle de Aranguren y a los vecinos del Valle por el apoyo económico y la colaboración ejemplar, así como la asistencia y ayuda del Gobierno de Navarra.

Este artículo se enmarca en una Tesis Doctoral be $\neg$ cada con la ayuda de la UPV/EHU PIF 2019, participado por el Grupo de Investigación en Prehistoria IT1223-19. Los autores reconocen el trabajo de todas las personas que han participado en el pro $\neg$ yecto, en particular al equipo de excavación y la Sección de Arqueología de la Sociedad de Ciencias Aranzadi. Finalmente, agradecer a Josu Narbarte Hernández y a los revisores anónimos por las aportaciones realizadas para mejorar el texto final.

\begin{tabular}{|c|c|c|c|c|c|}
\hline TORRES & ALJIBE & ESTANCIAS & PATIO EN LOS. & TERRITORIO & BIBLIOGRAFIA \\
\hline $\mathrm{SI}$ & $\mathrm{SI}$ & $\mathrm{SI}$ & $\mathrm{SI}$ & $\mathrm{N}$ & Bienes y Sola, 2015 \\
\hline NO & $\mathrm{SI}$ & NO & NO & B. & Garcia-Camino, 2004 \\
\hline NO & $\mathrm{SI}$ & $\mathrm{SI}$ & $\mathrm{NO}$ & $\mathrm{N}$. & Sagredo, 2018 \\
\hline NO & NO & $\mathrm{NO}$ & $\mathrm{NO}$ & $\mathrm{G}$. & Puyal, 2019 \\
\hline $\mathrm{SI}$ & $\mathrm{SI}$ & $\mathrm{SI}$ & $\mathrm{NO}$ & $\mathrm{N}$. & Agirre-Mauleon, 2017 \\
\hline $\mathrm{NO}$ & $\mathrm{NO}$ & $\mathrm{NO}$ & $\mathrm{NO}$ & G. & Padilla, 2000 \\
\hline NO & NO & $\mathrm{NO}$ & $\mathrm{NO}$ & G. & Agirre-Mauleon, 2017 \\
\hline NO & NO & $\mathrm{SI}$ & $\mathrm{NO}$ & $\mathrm{N}$. & Ramos, 2012 \\
\hline $\mathrm{SI}$ & $\mathrm{NO}$ & $\mathrm{SI}$ & $\mathrm{NO}$ & B. & Neira, 2012 \\
\hline $\mathrm{NO}$ & $\mathrm{SI}$ & $\mathrm{SI}$ & $\mathrm{NO}$ & $\mathrm{N}$. & Sagredo, 2006 \\
\hline $\mathrm{SI}$ & NO & $\mathrm{SI}$ & $\mathrm{NO}$ & $\mathrm{N}$ & Zabala, 2003 \\
\hline $\mathrm{SI}$ & $\mathrm{SI}$ & $\mathrm{SI}$ & $\mathrm{SI}$ & $\mathrm{N}$. & Buces et al. 2013 \\
\hline $\mathrm{SI}$ & $\mathrm{SI}$ & $\mathrm{SI}$ & $\mathrm{NO}$ & $\mathrm{N}$. & Satrustegi, 1973; Sagredo, 2018 \\
\hline $\mathrm{NO}$ & $\mathrm{SI}$ & $\mathrm{NO}$ & $\mathrm{NO}$ & G. & Barandiaran, 1977 \\
\hline NO & SI & $\mathrm{SI}$ & NO & A. & Solaun, 2002 \\
\hline $\mathrm{NO}$ & $\mathrm{SI}$ & $\mathrm{SI}$ & $\mathrm{NO}$ & $\mathrm{G}$. & Alvaro y Trave, 2019 \\
\hline $\mathrm{NO}$ & $\mathrm{NO}$ & $\mathrm{NO}$ & $\mathrm{NO}$ & $\mathrm{N}$. & Ramos, 2012 \\
\hline $\mathrm{SI}$ & $\mathrm{SI}$ & $\mathrm{SI}$ & $\mathrm{NO}$ & $\mathrm{N}$. & Chafer, 2001 \\
\hline $\mathrm{NO}$ & NO & NO & NO & $\mathrm{N}$. & Castiella et al. 1999 \\
\hline NO & $\mathrm{SI}$ & NO & NO & $\mathrm{N}$. & Sagredo, 2018 \\
\hline $\mathrm{SI}$ & NO & $\mathrm{SI}$ & $\mathrm{NO}$ & A. & Azkarate y Solaun, 2007 \\
\hline $\mathrm{NO}$ & NO & $\mathrm{NO}$ & $\mathrm{NO}$ & $\mathrm{N}$. & García y Sesma, 2015 \\
\hline $\mathrm{SI}$ & $\mathrm{SI}$ & NO & NO & $\mathrm{N}$. & Sagredo, 2006 \\
\hline NO & $\mathrm{SI}$ & $\mathrm{SI}$ & NO & A. & Solaun y Azcárate, 2016 \\
\hline $\mathrm{NO}$ & $\mathrm{NO}$ & $\mathrm{SI}$ & $\mathrm{NO}$ & $\mathrm{G}$. & García, 1987; Moraza y Ceberio, 2009 \\
\hline $\mathrm{SI}$ & $\mathrm{SI}$ & $\mathrm{SI}$ & $\mathrm{SI}$ & $\mathrm{N}$. & Del Olmo, 2014 \\
\hline $\mathrm{SI}$ & NO & $\mathrm{SI}$ & $\mathrm{SI}$ & $\mathrm{N}$. & Ramos, 2001 \\
\hline NO & $\mathrm{SI}$ & NO & NO & B. & Solaun e Hidalgo, 2008 \\
\hline $\mathrm{SI}$ & NO & SI & NO & A. & Plata Y Solaun, 2009 \\
\hline NO & $\mathrm{NO}$ & $\mathrm{SI}$ & NO & B.N. & Martikorena et al. 2013 \\
\hline
\end{tabular}




\section{BIBLIOGRAFÍA}

Agirre-Mauleon, J., 2017a. Memoria arqueológica del Castillo de Amaiur. Sociedad de Ciencias Aranzadi. Inédito.

Agirre-Mauleon, J., 2017b. Castillo de Beloaga. Arkeoikuska 2017, 389-390.

Aiestaran, M., Buces, J., 2017. Memoria arqueológica del castillo de Irulegi. Sociedad de Ciencias Aranzadi. Inédito.

Aiestaran, M., Ruiz-González, D., 2020. Memoria arqueológica del poblado de Irulegi. Sociedad de Ciencias Aranzadi. Inédito.

Alvaro, K., Travé, E., 2019. Los materiales arqueológicos de la fortaleza de Mendikute, Gipuzkoa (s. XII XIV): elementos para el estudio de la vida cotidiana en un asentamiento militar. Munibe Antropologia-Arkeologia 70, 319-334.

Arrese, A. 2011. Jentilbaratza gotorlekua. Arkeoikuska 2011, 336-337.

Azkarate, A., Solaun, J.L., 2007. Peña del Castillo (Marquínez), Arkeoikuska 2007, 62-67.

Bienes, J.J., 2004. La fortificación islámica en el Valle Medio. En: De La Casa Martínez, C., Martínez, Y. (coord.), Cuando las horas primeras: en el Milenario de la batalla de Catalañazor, 285-301. Universidad internacional Alfonso VIII.

Bienes, J.J., Sola, O., 2015. La torre mayor del castillo de Ablitas. Marcas de cantería. Trabajos de Arqueología Navarra 27, 257-268.

Bruley-Chabot, G., Warme, N., 2009. Approche expérimentale pour la compréhension des fours culinaires du haut Moyen âge: bilan critique et perspectives. In: L'actualité de l'archéologie du haut Moyen-Âge en Picardie. Les apports de l'expérimentation à l'archéologie mérovingienne. Actes des XXIXe journées internationales d'archéologie mérovingiennes. Musée des Temps Barbare, Marle (Aisne) 26-28 septembre 2008, 121-128. Revue archéologique de Picardie 1-2.

Buces, J., Aiestaran, M., 2016. Memoria arqueológica del castillo de Irulegi. Sociedad de Ciencias Aranzadi. Inédito.

Buces, J., Moraza, A., Agirre, J., Pescador, A., Legorburu, M., 2013. Un enclave estratégico en la Cuenca de Pamplona: el castillo medieval de Irulegi (Lakidain, Navarra). Balance de los trabajos arqueológicos (2007-2012). Trabajos de Arqueología Navarra 25, 143-167.

Cabodevilla, I., 2018. La arquitectura defensiva de la Corona de Aragón en los siglos XIV y XV. Entre la ballesta y la pólvora. EGA: revista de expresión gráfica arquitectónica 23, 103-117.

Castán, A., 2019. Castillos del siglo XI en la provincia de Huesca. El largo camino. Prames, Zaragoza.

Cañada, F., Faro-Carvalla, J.A., Unzú, M., 2005. El Cerco de Artajona. Estudio histórico-arqueológico. Trabajos de Arqueología Navarra 18, 175-300.

Cañavate, V., 2008. Estructuras domésticas de época altomedieval en el Sureste peninsular: el Tolmo de Minateda (Hellín, Albacete). Instituto de Estudios Albacetenses «Don Juan Manuel», Albacete.

Castiella, A., Sesma, J., García, M.L., García, J., Prieto, J.J., Faro, J.A., García, D., 1999. Poblamiento y territorialidad en la Cuenca de Pamplona: una visión arqueológica. Cuadernos de Arqueología de la Universidad de Navarra 7(1), 9-309.

Carandini, A., 1997. Historias de la tierra. Crítica, Barcelona.

Chafer, G., 2001. Una inscripción onomástica en el castillo de Monreal (Navarra). Trabajos de Arqueología Navarra 15, 335-344.
Del Olmo, M., 2014. Intervenciones en el castillo de Santacara. En: Castillos de España: publicación de la Asociación Española de Amigos de los Castillos 175-178, 111-116.

Faro, J.A., García-Barberena, M., Unzú, M., 2007-2008. Pamplona y el Islam: nuevos testimonios arqueológicos. Trabajos de Arqueología Navarra 20, 229-284.

García, M.L., Sesma, J., 2015. Aproximación arqueológica al castillo de Peñaflor (Vedado de Eguaras, Valtierra). Revista del centro de estudios Merindad de Tudela 23, 129-164.

Garcia-Camino, I., 2004. Arqueología medieval en Bizkaia: hipótesis y perspectivas de investigación. Kobie Anejos 6, 537-558.

Gil, J., 2013. Fundamentos constructivos de las fortificaciones fronterizas entre las coronas de Castilla y Aragón de los siglos XII al XV en la actual provincia de Soria. Tesis doctoral, Departamento de Construcción y Tecnología Arquitectónicas, Escuela Técnica Superior de Arquitectura de Madrid.

Harris, E., 1991. Principios de Estratigrafía Arqueológica. Crítica, Barcelona.

Iriarte, P., 2016. Baztan, paisaia eta etnografía. Baztango Udala.

Jimeno Jurío, J.M., 2016. La alimentación en Monreal: trabajo de campo etnográfico, Cuadernos de Etnología y Etnografía de Navarra 90, 433-473.

Jimeno Jurío, J.M., 2006. La Navarra Medieval. Pamiela, Iruña.

Lazcano, M.R., 2011. Santa María de Ujué. Fundación para la Conservación del Patrimonio Histórico de Navarra.

Lizeaga, J., 2018. Gongora-ko (Nafarroa) Jauregizaharra jauregiaren datazio dendrokronologikoa, Munibe Antropologia-Arkeologia 69, 333-341.

Marticorena, P., Berdoy, A., Convertini, F., Dumontier, P., Manceau, L., Nicolas, C., Parent, G., 2013. Le site de Zerkupe (Saint-Jean-Pied-de-Port, Pyrénées-Atlantiques): Une occupation domestique de plein air du Bronze final et un site fortifié du Moyen-Age et de l'époque moderne. Archéologie des Pyrénées Occidentales et des Landes 30, 13-21.

Martinena, J.J., 1994. Castillos reales de Navarra (siglos XIII-XVI). Gobierno de Navarra, Pamplona.

Martinena, J.J., 2017. El Castillo de Irulegi. Zangotzarra 21, 40-65.

Martínez, J.A., 1987. Los castillos románicos y la tipología "Felipe Augusto": su reflejo en las fortalezas aragonesas. En: Homenaje a D. Federico Balaguer Sánchez, 43-64. Instituto de estudios altoaragoneses.

MOLAS, 1994. Archaeological site manual. Museum of London.

Monteano, P., 1999. Los navarros ante el hambre, la peste, la guerra y la fiscalidad. Siglos XV y XVI. UPNA-NUP, Iruñea.

Mora-Figueroa, L., 2006. Glosario de arquitectura defensiva medieval. Ministe $\neg$ rio de Defensa, Madrid.

Moraza, A., Moro, I., Mujika-Alustiza, J.A, 2003. Contribución al estudio de las estructuras tumulares en arqueología. Entre la similitud morfológica y la disparidad de funciones. Veleia 20, 243-272.

Neira, M., 2012. Monte Ereñozar. Arkeoikuska 12, 251-255.

Nuín, J., Borja, J.A., 1991. El poblamiento holocénico y su medio en las cuencas prepirenaicas de Pamplona y Aoiz-Lumbier. Isturitz Cuadernos de Prehistoria-Arqueología 4, 61-96.

Padilla J.I., 2000. Fortaleza medieval de Ausa Gaztelu (Zaldibia). Arkeoikuska 99, 109. 
Pescador, A., 2020. El Castillo de Irulegi. Historia y documentos. Sociedad de Ciencias Aranzadi. Inédito.

Pérez, F., 1983. Ermitas de Navarra. CAN, Pamplona.

Plata, A., Solaun, J.L., 2008. Plan de castillos de la CAV. Arkeoikuska 2009, 23-42

Ponce-Antón, G., Lindroos, A., Ringbom, A., Ortega, L.A., Zuluaga, M.C., Hajdas, I., Olsen, J., Agirre-Mauleon, J., 2020. Comparison of sample preparation procedures for mortar radiocarbon dating. Case study of Irulegi Castle (Navarre, Spain). Quaternary Geochronology 60, 101110.

Puyal, M., 2019. Atxorrotz gaztelua (lehen "Aitzorrotz" deitua). Arkeoikuska 18, 427-431.

Quirós, J.A., Tejado, J.M. (eds.), 2012. Los castillos altomedievales en el noroeste de la Península Ibérica. UPV-EHU, Gasteiz.

Ramos, M., 2000. La frontera occidental del reino de Navarra en 1200: la perspectiva arqueológica. Eusko lkaskuntzen Nazioarteko Aldizkaria 45(2), 495-538.

Ramos, M., 2001. Excavaciones en el castillo de Tiebas (Navarra), primer informe provisional, 1998. Trabajos de Arqueología Navarra 15, 167-214.

Ramos, M., 2012. Los castillos altomedievales en Navarra (450-1000). En: Quirós, J.A., Tejado, J.M. (eds.). Los castillos altomedievales en el noroeste de la Península Ibérica, 145162. UPV-EHU, Gasteiz.

Ramos, M., 2015. Intervenciones arqueológicas en el castillo de Estella (2001-2010). Trabajos de Arqueología Navarra 27 185-220.

Sagredo, I., 2006. Navarra, castillos que defendieron el Reino, Tomo I. Pamiela, Iruñea.

Sagredo, I., 2018. Intervenciones arqueológicas en los castillos roqueros de Irurita, Aitzita y Ortzorrotz. Sistema defensivo de la merindad de las Montañas, Trabajos de Arqueología Navarra 30, 93-151.

Sarasola, N., 2010. El poblamiento medieval de Gipuzkoa Revisión crítica del registro arqueológico. Munibe Antropologia-Arkeologia 61, 338-393.

Sarasola, N., Moraza, A., 2011. Arkeologia 0.5. Erdi Aroko Arkeologia Gipuzkoan = Arqueología medieval en Gipuzkoa. Diputación Foral de Gipuzkoa, Donostia-San Sebastián.

Satrustegui, J.M., 1973. La cueva artificial de "Jentilen sukaldean" de Urdiain, Cuadernos de Etnología y etnografía de Navarra 13, 5-28

Sesma, J., Tabar, M.I., 2001. El castillo de Marcilla: Intervención arqueológica, 1998. Trabajos de Arqueología Navarra 15, 215-168.

Solaun, J.L., 2002. Castillo de Ocio (Zambrana): I Campaña. Arkeoikuska 2002, 209-221.

Solaun, J.L., Azkarate, A., 2016. El castillo de Portilla (Zambrana, Alava). Origen y significado de una fortaleza plenomedieval en territorio alavés (siglos XI-XII). Munibe Antropologia-Arkeologia 67, 167-183.

Solaun, J.L., Hidalgo, J., 2008. El castillo de Untzueta. Una fortaleza del señor de Bizkaia, Aunia 25, 27-45.

Tabar, M.I., 1994. El desolado de Rada. 1991-1992. Trabajos de Arqueología Navarra 11, 312-315.
Tabar, M.I., 1996. Intervenciones arqueológicas en el desolado de Rada: 1994-1995. Trabajos de Arqueología Navarra 12, 338-342.

Tapia, J., Ceberio, M., Moraza, A., 2019. Iraganera bidaia bat, San Adrian-Lizarrate tunela: 14.000 urteko historia. Zegamako Udala, Zegama.

Tejado, J.M., 2010. Arqueología y gestión del territorio en el alto Valle del Iregua: el castro de "El Castillo de los Monjes" (Lumbreras, La Rioja). Tesis Doctoral, Universidad de la Rioja.

Toubert, P., 1990. Castillos, señores y campesinos en la Italia medieval. Crítica, Barcelona.

Vigil-Escalera, A., 2012. Apuntes sobre la arquitectura de los hogares y hornos domésticos altomedievales del centro de la península Ibérica (siglos V-VIII d.C.), Arqueología de la arquitectura 9, 165-180.

Zabala, L., 2003. El castillo de Gorriti. Un pueblo recupera su memoria. Concejo de Gorriti, Basauri. 
